\title{
A REVOLTA DE CANUDOS: POSSÍVEIS REFLEXÕES ENTRE MESSIANISMO, MOVIMENTO SOCIAL E PSICOPATOLOGIA PELA NÃO CONFIGURAÇÃO DA VIOLÊNCIA RELIGIOSA NA CONTEMPORANEIDADE ${ }^{1}$
}

\section{The Canude revolt: possible reflections between messianism, social movement and psychopathology for the non-configuration of religious violence in contemporaneity}

Flavio da Silva Chaves ${ }^{2}$

\section{Resumo:}

O presente trabalho tem por objetivo pensar a não configuração da violência religiosa na contemporaneidade ao refletir o paradoxo da missão na Revolta de Canudos entre a messianidade, o movimento social e possíveis reflexos psicopatológicos no líder comunitário Antônio Conselheiro. A análise será feita a partir da pesquisa bibliográfica. Em primeiro lugar, será descortinado a história da Revolta dos Canudos, o pensamento do seu líder, o fator motivacional que desencadeou a guerra e a relação entre as revelações messiânicas e o movimento social. Em seguida, inferem-se algumas reflexões sobre a psicose e comportamentos que se desdobram em atos de violência, tendo como fundamento as supostas revelações religiosas. E por último, buscamos elencar algumas considerações que apresentem o paradoxo entre messianidade e questões patológicas advindo da religião, tendo como objetivo a não configuração da violência religiosa, sem perder de vista a busca por justiça e igualdade social. Conclui-se que, conquanto não seja possível abalizar, por meio da literatura, o paradoxo entre messianismo, movimento social e psicopatologia na Revolta de Canudos, a pesquisa é pertinente por provocar novos debates no intuito de trazer novas ponderações pela não configuração da violência religiosa, em qualquer âmbito, sob quaisquer condições.

Palavras-chaves: Revolta de Canudos; messianidade; movimento social; psicopatologia; violência religiosa.

\section{Abstract:}

The present work aims to think about the non-configuration of religious violence in contemporary times by reflecting the paradox of the mission in the Canudos Revolt between messianity, the social movement and possible psychopathological reflexes in the community leader Antônio Conselheiro. The analysis will be based on bibliographic research. First, the story of the Canudos Revolt, the thought of its leader, the motivational factor that triggered the war and the relationship between the messianic revelations and the social movement will be revealed. Then, we infer some reflections on psychosis and behaviors that unfold in acts of

1 Submetido em: 18.02.2019. Aceito em: 08.08.2020.

2 Graduação em Psicologia pela Universidade Estácio de Sá, RJ, e em Teologia pela Faculdade Unida de Vitória, ES. Especialização em Gestão Ministerial e Psicoterapia Existencial e Gestalt Terapia. Mestrado em Ciências das Religiões pela Faculdade Unida de Vitória, ES. Contato: flavio.chaves.silva@hotmail.com

Protestantismo em Revista | São Leopoldo | v. 46, n. 01 | p. 148-167| Jan./jun. 2020

Disponível em: <http://periodicos.est.edu.br/index.php/nepp> 
violence, based on the supposed religious revelations. And finally, we seek to list some considerations that present the paradox between messianity and pathological issues arising from religion, with the objective of not configuring religious violence, without losing sight of the search for justice and social equality. It is concluded that, although it is not possible to assess, through literature, the paradox between messianism, social movement and psychopathology in the Canudos Revolt, the research is pertinent because it provokes new debates in order to bring new considerations for the non-configuration of religious violence, in any scope, under any conditions.

Keywords: Canudos revolt; messiancy; social movement; psychopathology; religious violence.

\section{Introdução}

O presente trabalho tem por objetivo pensar a não configuração da violência religiosa na contemporaneidade ao refletir o paradoxo da missão na Revolta de Canudos entre a messianidade, o movimento social e possíveis reflexos psicopatológicos no líder comunitário Antônio Conselheiro. A análise será feita a partir da pesquisa bibliográfica. Em primeiro lugar, será descortinado a história da Revolta dos Canudos, o pensamento do seu líder, o fator motivacional que desencadeou a guerra e a relação entre as revelações messiânicas e o movimento social. Em seguida, inferem-se algumas reflexões sobre a psicose e comportamentos que se desdobram em atos de violência, tendo como fundamento as supostas revelações religiosas. Por último, buscamos elencar algumas considerações que apresentem o paradoxo entre messianidade e questões patológicas advindo da religião, tendo como objetivo a não configuração da violência religiosa, sem perder de vista a busca por justiça e igualdade social.

A pesquisa é uma provocação, um convite à reflexão, uma vez que não dispomos de elementos para uma análise psicológica do seu líder. Também não existe a pretensão de fazer juízo de valor. O que se pretende, tão somente, é trazer à baila a questão da violência religiosa e, desta forma, repensar, no contexto contemporâneo, as mais variadas formas de patologias e a sua relação com os atos de violência religiosa. Deixando claro, no entanto, que, mesmo na batalha sangrenta que marcou a Revolta dos Canudos, caos e ordem são linhas paradoxais nos movimentos religiosos.

A pesquisa se justifica pela onda de violência que marca a história contemporânea, e muitas destas chanceladas por motivações religiosas, marcadas pela intolerância de grupos majoritários que sucumbem os direitos dos menos favorecidos, como é o caso de Canudos. Concomitantemente, em busca de direitos, justifica-se a violência? $\mathrm{O}$ assunto é complexo, provocando conflitos e promovendo debates intermináveis no campo acadêmico, político e religioso. No objetivo de promover a igualdade de direitos, respeitar o modo de cada um se colocar no mundo e, concomitantemente, diferenciar o que é messiânico do que é patológico nas reivindicações sociais, passemos à análise da pesquisa. 


\title{
Antônio Conselheiro e a Revolta dos Canudos: Perspectiva Histórica
}

A Guerra de Canudos "envolve um conflito entre o exército brasileiro e os milhares de sertanejos pobres que vivem numa comunidade autossuficiente, agrupados em torno de Antônio Conselheiro, líder religioso, na localidade que é chamada de Belo Monte" ${ }^{3}$, no Nordeste da Bahia. O contexto do conflito se dá após a instauração da República em 1889, trazendo uma nova configuração política e social, dentre elas, a separação Igreja e Estado. Algumas medidas foram adotadas que contrariavam os interesses do catolicismo popular dos canudenses, tais como: "o registro civil de nascimento, casamento e morte e a cobrança de novos impostos" ${ }^{4}$.

Segundo Junqueira, "A Guerra de Canudos pode ser compreendida no quadro de movimentos sociais que eclodiram em alguns pontos do território nacional e sacudiram a República nascente, a partir da primeira Revolta da Armada (1893) até a Guerra do Contestado (1912-1914)"5. Nesta perspectiva, o retrato do Brasil cartografado por Schwarcz e Starling ${ }^{6}$ é a elite política, demarcada pelo patrimonialismo e patriarcalismo, onde o Estado é o provedor da população, destituindo dos cidadãos os seus direitos, herança dos colonizadores. Neste contexto, as revoltas, as guerras e os conflitos são analisados pelo viés da luta pela cidadania e a busca por sua própria identidade.

\begin{abstract}
Mas vale a pena anotar outro traço que, se não é natural, pois tratamos aqui de construções sociais e não biológicas, é escandalosamente resistente e tem lugar cativo na história brasileira. Certa lógica e certa linguagem da violência trazem consigo uma determinação cultural profunda. Como se fosse um verdadeiro nó nacional, a violência está encravada na mais remota história do Brasil, país cuja vida social foi marcada pela escravidão. Fruto da nossa herança escravocrata, a trama dessa violência é comum a toda a sociedade, se espalhou pelo território nacional e foi assim naturalizada. Se a escravidão ficou no passado, sua história continua a se escrever no presente. A experiência de violência e dor se repõe, resiste e se dispersa na trajetória do Brasil moderno, estilhaçada em milhares de modalidades de manifestação [...]. A colonização levou à exploração do trabalho indígena e foi responsável por muita dizimação. É ainda na conta da colonização que se deve pôr o recrudescimento das guerras indígenas, que, se já existiam internamente, eram agora provocadas também pelos colonos, os quais faziam aliados na mesma velocidade com que criavam inimigos. ${ }^{7}$
\end{abstract}

Desta feita, os atos de violência são vistos sob a ótica da busca de direitos num Brasil eminentemente escravagista.

Os escravizados jamais abriram mão de serem agentes e senhores de suas vidas. Em primeiro lugar, criaram entre si laços de afeição, associações religiosas e sociais, e

3 COSTA, Carla. Cronologia resumida da Guerra de Canudos. Museu da República, IBRAM/Minc, outubro de 2017. p. iv. Disponível em: <http://museudarepublica.museus.gov.br/wp content/uploads/2017/10/CronoCanudos.pdf> Acesso em: 12 dez. 2018.

4 COSTA, 2017, p. iv.

5 JUNQUEIRA, Eduardo. Guerra de Canudos. Disponível em: <https://cpdoc.fgv.br/sites/default/files/verbetes/primeira-republica/GUERRA\%20DE\%20CANUDOS.pdf> Acesso em: 12 dez. 2018, p. 1.

6 SCHWARCZ, Lilia M.; STARLING, Heloísa M. Brasil: uma biografia. São Paulo: Companhia das Letras, 2015. Acervo Eletrônico. Disponível em: <https://docero.com.br/doc/s5n0c> Acesso em: 10 jul. 2020.

7 SCHWARCZ; STARLING, 2015, p. 10; 32.

Protestantismo em Revista | São Leopoldo | v. 46, n. 01 | p. 148-167| Jan./jun. 2020

Disponível em: <http://periodicos.est.edu.br/index.php/nepp> 
redes. [...] reagiram ao cotidiano violento também de forma violenta, sendo frequentes as fugas - individuais e em massa - os assassinatos de feitores e senhores, e as insurreições organizadas. ${ }^{8}$

Leão ${ }^{9}$, a partir da análise de dois jornais da capital federal da época, considera que o conflito foi uma manifestação de força republicana na consolidação do novo tipo de regime político.

\begin{abstract}
Mudanças políticas implicam na criação ou reafirmação de símbolos e valores que podem vir a constituir uma cultura política que legitime o novo regime. A República ainda não havia conseguido a estabilidade desejada para garantir a continuidade do regime, e o conflito foi visto como uma oportunidade de consolidar a cultura republicana no Brasil, criando-se nas páginas destes jornais o ideal de patriotismo do novo regime, bem como seus heróis e inimigos. ${ }^{10}$
\end{abstract}

Polêmicas, bandidos e mocinhos, são as faces de uma mesma moeda na avaliação da Guerra de Canudos. Para uns, os monarquistas de Conselheiro, uma referência aos seguidores de Antônio Conselheiro, eram baderneiros, anarquistas. Para outros, heróis, revolucionários, promotores da inserção social que, no confronto com as forças opressoras do Brasil República, acolhem os excluídos socialmente. Euclides da Cunha (1866-1909), escritor, jornalista e professor brasileiro, autor da obra "Os Sertões", foi o principal representante do jornal O Estado de São Paulo para cobrir a guerra no município de Canudos. Segundo Leão, este autor apresenta duas interpretações para o evento, em que, no primeiro momento, os sertanejos são classificados enquanto monarquistas de Conselheiro e, após a Guerra, heróis ${ }^{11}$.

E, nas páginas de Os Sertões, o autor resume o que considera ser o verdadeiro espírito do sertanejo em poucas palavras: ele "é, antes de tudo, um forte" 4 . Com esta frase simples, Cunha descreveu todo o ânimo do homem do sertão. Homem este que foi transformado em vilão ao longo do quase um ano de guerra no sertão da Bahia. O "Hércules-Quasímodo" ganhou ares de fanático incorrigível, de bandido, inimigo maior da República que ainda vivia seus primeiros anos. ${ }^{12}$

A República assim definiu, abalizou e classificou o homem do sertão. Era o conflito litoral/República versus sertão/Monarquia. Quais foram, no entanto, as motivações para o conflito, que cabe uma releitura pelo viés da violência religiosa? Primeiro, a figura emblemática do seu principal líder: Antônio Vicente Mendes Maciel. Nascido no dia 13 de março de 1830, filho do comerciante Vicente Mendes Maciel e de Maria Joaquina do Nascimento, em Quixeramobim, na província do Ceará. Após ser abandonado pela esposa Brasilina Laurentina de Lima, com quem se casara em 1857, Antônio Conselheiro, assim era chamado, "começa uma vida de peregrino, fazendo orações e penitências em companhia de um grupo de fiéis, que o segue pelas estradas e lugarejos do interior" ${ }^{13}$. Segundo, são as motivações para a luta em nome de Deus: questões sociais e a defesa de um regime político

8 SCHWARCZ; STARLING, 2015, p. 33.

9 Leão, Maria Beatriz da Costa Baptista de. A guerra de Canudos e a cultura republicana nos jornais da capital federal. Dissertação (Mestrado em História) - Pontifícia Universidade Católica do Rio de Janeiro, Departamento de História, 2015, p. 5.

10 LEÃO, 2015, p. 5.

11 CUNHA, 1897 apud. LEÃO, 2015, p. 9.

12 LEÃO, 2015, p. 9.

13 COSTA, 2017, p. 2.

Protestantismo em Revista | São Leopoldo | v. 46, n. 01 | p. 148-167| Jan./jun. 2020

Disponível em: <http://periodicos.est.edu.br/index.php/nepp> 
religioso monárquico? Reitera-se que outros movimentos sociais ocorreram enquanto resistência ao estabelecimento da monarquia: Revolta da Armada (1893) no Rio de Janeiro, em oposição a Floriano Peixoto; Revolta Federalista (1893) no Rio Grande do Sul; Revolta da Chibata ou Revolta dos Marinheiros (1910), reivindicando igualdade nas relações dentro da Armada e eliminação do castigo de chibata, dentre outras.

Segundo Costa, em 15 de novembro de 1889, o Marechal Deodoro da Fonseca,

lidera o golpe que derruba a monarquia e instaura a República, movimento político que ocorre sem qualquer participação popular. Além do fim da monarquia, o novo regime de governo vai introduzir mudanças como eleições diretas, novos impostos, separação entre igreja e estado, liberdade de culto, registro civil de nascimento, casamento e óbito. Essas transformações são consideradas perturbadoras e disruptivas por Antônio Conselheiro e seguidores e causam medo e apreensão nos fiéis. Eles vivem num mundo patriarcal e são devotos de um catolicismo tradicional popular que reverencia o regime monárquico e a figura do imperador D. Pedro II, visto como um rei eterno e paternal. ${ }^{14}$

Por este viés, a luta de Conselheiro era político-ideológica, em nome da tradição religiosa. Tal ponto de vista é compartilhado por Nogueira ao afirmar: "Independentemente de estarem certos ou errados, a Guerra de Canudos também dividiu opiniões. De um lado, estavam milhares de pessoas que queriam a consolidação da República e, do outro, os que queriam o retorno da Monarquia, bem como a volta da família real para o Brasil" ${ }^{15}$.

Por outro lado, Moura ${ }^{16}$ analisa a Guerra de Canudos pelo viés sociológico, como "uma resistência ao monopólio da propriedade da terra em nosso país - um dos pontos cruciais de nosso atraso econômico e social"17. Assim sendo, a Guerra de Canudos pode ser vista como um movimento social pelas lentes da manifestação da religiosidade popular, "ou como um simples episódio de misticismo, no qual as populações sertanejas expressaram os seus sentimentos de fanatismo religioso"18.

Cunha ${ }^{19}$ retrata de forma vívida as lutas, os conflitos, escrita com lágrimas e sangue, a Revolta de Canudos. É qualificado, por seus editores, como "livro emocional"20, uma referência à Psicologia dos Sertanejos. Antônio Conselheiro se apresenta como um Messias no arraial de Canudos. "Evangelizador e sacerdote de uma crença devotadíssima a Deus, ele dominava espiritualmente sobre os seus conterrâneos sertanejos e agia como se fosse uma

14 COSTA, 2017, p. 6.

15 NOGUEIRA, Ana Paula dos Santos. Canudos: uma história de morte, na luta pela vida. Disponível em: <http://www.uesb.br/anpuhba/artigos/anpuh_I/ana_paula_santos_nogueira.pdf> Acesso em: 12 dez. 2018, p. 1.

16 MOURA, Clóvis. Sociologia política da Guerra Camponesa de Canudos: da destruição do Belo Monte ao aparecimento do MST. 1. ed. Editora Expressão Popular: São Paulo, 2000. p. 14. Disponível em: <http://www.reformaagrariaemdados.org.br/sites/default/files/Sociologia\%20pol\%C3\%ADtica\%20da\%20gu erra\%20camponesa\%20de\%20Canudos\%20\%20da\%20destrui\%C3\%A7\%C3\%A3o\%20do\%20Belo\%20Monte \%20ao\%20aparecimento\%20do\%20MST\%20\%20Cl\%C3\%B3vis\%20Moura\%20\%20Express\%C3\%A3o\%20Pop ular\%20-\%202000.pdf> Acesso em: 12 dez. 2018.

17 MOURA, 2000, p. 14.

18 MOURA, 2000, p. 21.

19 CUNHA, Euclydes da. Os sertões: campanha dos canudos. 2. ed. Rio de Janeiro: LAEMMERT \& C, 1904.

20 Cf. CUNHA, 1904, p. 7. O termo é uma descrição aos fatores emocionais tanto do seu líder quanto dos povos envolvidos na batalha dos canudos.

Protestantismo em Revista | São Leopoldo | v. 46, n. 01 | p. 148-167| Jan./jun. 2020

Disponível em: <http://periodicos.est.edu.br/index.php/nepp> 
sombra que baixasse do azul celeste"21. Ladainhas, terços, orações, procissões eram as marcas dos adeptos e seguidores do profeta Antônio Conselheiro. Desta forma, o seu carisma constituía um risco para a ordem constituída, a República.

Em nome de Deus, no acampamento, viveu-se a igualdade e a justiça social, "um modo alternativo de vida que retira os conselheiristas das esferas de poder da propriedade, da igreja e da justiça, representados pelo dono de terras, pelo padre e pelo delegado" ${ }^{22}$. Para os devotos,

Belo Monte é um lugar onde podem viver de acordo com a lei de Deus, dentro de uma rotina controlada e segura, longe da fome, da privação e das ameaças do mundo moderno. Eles querem viver em paz e alcançar a redenção, longe de um mundo ameaçador. Vivem sob a tríade da fé, penitência e esperança. Belo Monte atrai em torno de 15.000 sertanejos, traumatizados pelos anos de privação, pelas secas periódicas, pela dominação dos grandes proprietários e pelos conflitos entre clãs regionais. Eles são vaqueiros, meeiros, parceiros e jornaleiros - ex-escravos, índios, mestiços - que sozinhos ou com famílias inteiras se deslocam para Belo Monte na esperança de uma vida melhor ${ }^{23}$.

Nas palavras de Martins ${ }^{24}$,

Antônio Conselheiro e seus seguidores protagonizaram no semiárido sertanejo do Belo Monte (Bahia, 1893-97) um curioso empreendimento comunitário, que alcançou o expressivo crescimento populacional de $10335 \%$ em apenas quatro anos de existência e que resistiu, por quase 10 meses, às investidas de cerca da metade do efetivo da força terrestre brasileira de então.

Segundo Costa, o êxodo rural dos trabalhadores ocorrido em Belo Monte, abala os dois centros de poder dos proprietários de terra: "a mão de obra disponível e a vasta clientela que os donos do poder podem dispor para usá-la nas eleições com o voto de cabresto" 25 . Paradoxalmente, Wanderle ${ }^{26}$ apresenta o conflito religioso entre o poder do Estado e da Igreja versus o Catolicismo do Sertão. Pontualmente, destaca duas tendências em transição no período em que ocorre a guerra: o Catolicismo reformado/romanizado, defendido pelos Bispos católicos em detrimento do Catolicismo tradicional, o pensamento ideológico religioso de Antônio Conselheiro.

Herdeiro do secular legado do catolicismo tradicional - com certas variações de sentido também denominado de popular ${ }^{11}$, rústico ${ }^{12}$, místico ${ }^{13}$ - o conselheirismo se encontra situado num momento - finais do século XIX - particularmente intenso do movimento de transição em direção ao modelo romano. Movimento este que tem sua força principal na ação sistemática e persistente dos bispos reformadores que, sobretudo a partir do advento da República, e com o auxílio de ordens religiosas

21 CUNHA, 1904, p. 8.

22 COSTA, 2017, p. 9.

23 COSTA, 2017, p. 10.

24 MARTINS, Paulo Emílio Matos. Canudos: organização, poder e o processo de institucionalização de um modelo de governança comunitária. Cadernos EBAPE. BR, v. 5, nํ 4, dez. 2007, p. 1.

25 COSTA, 2017, p. 10.

26 WANDERLEI, Leandro Aquino. Religiosidade e conflito no sertão conselheirista: o antagonismo entre a arquidiocese de Salvador e Antônio Conselheiro/Canudos. Anais do XXVI Simpósio Nacional de História ANPUH. São Paulo, julho 2011, p. 1-15.

Protestantismo em Revista | São Leopoldo | v. 46, n. 01 | p. 148-167| Jan./jun. 2020

Disponível em: <http://periodicos.est.edu.br/index.php/nepp> 
estrangeiras, buscaram redefinir o lugar do clero frente à sociedade brasileira em geral e ao Estado em particular ${ }^{27}$.

Campos $^{28}$ destaca a dimensão da tragédia. "O conflito deixou aproximadamente vinte mil mortos" 29 , com a devida aquiescência de dois jornais Protestantes da época: ' $O$ Estandarte', dos presbiterianos; e 'O Expositor Cristão', dos metodistas" ${ }^{30}$, que adotaram a mesma postura crítica dos jornais seculares, na oposição a Canudos, "exceto na atribuição da causa da tragédia à religião dominante - o catolicismo" ${ }^{31}$.

Neste contexto, onde se configura a violência religiosa? Nas atitudes, digamos, messiânicas de Antônio Conselheiro ou na opressão da religião dominante? O assunto é complexo. Para Facó ${ }^{32}$, as lutas que envolveram aspectos messiânicos, de fundo místico, como Canudos, Juazeiro ${ }^{33}$ e o Contestado ${ }^{34}$, são os despertar dos pobres do campo. Em sua análise, o fenômeno messiânico de fato existiu, mas como exteriorização da materialidade e não como um fim em si mesmo.

Não negamos a existência do fenômeno, uma espécie de misticismo, de messianismo não cristão, embora formalmente influenciado pelo cristianismo. O que discutimos é a sua essência, a eclosão e motivação das lutas no falso pressuposto de que elas têm no misticismo ou messianismo sua origem e seu fim. Acreditamos, ao contrário, que os fenômenos de misticismo ou messianismo, que se convencionou chamar de fanatismo, disseminados pelos sertões em nosso passado ainda recente, têm um fundo perfeitamente material e servem apenas de cobertura a esse fundo. É a sua exteriorização ${ }^{35}$.

Logo, o que se designa de messiânico, era a explosão de sentimentos religiosos, próprios das populações subjugadas a um sistema de opressão. É o clamor por libertação. Daí a designação de fanáticos, agressivos e extremados.

[...] o sentimento é o órgão essencial da religião. Ao elaborarem variantes do cristianismo, as populações oprimidas do sertão separavam-se ideologicamente das classes e grupos que as dominavam, procurando suas próprias vias de libertação. As classes dominantes, por sua vez, tentando - justificar o seu esmagamento pelas

27 WANDERLEI, 2011, p. 4.

28 CAMPOS, Leonildo Silveira. Ecos da "Guerra de Canudos" em dois Jornais Protestantes de São Paulo (18961897). Estudos de Religião, v. 31, n. 1, 37-59, jan.-abr. 2017, p. 37-59.

29 CAMPOS, 2017, p. 37.

30 CAMPOS, 2017, p. 37.

31 CAMPOS, 2017, p. 37.

32 FACÓ, Rui. Cangaceiros e fanáticos: gênese e lutas. Disponível em: <https://www.marxists.org/portugues/faco/1963/03/cangaceiros.pdf> Acesso em: 19 dez. 2018. p. 8-228.

33 Ocorrida em 1914, em Juazeiro do Norte, no interior do Estado do Ceará, sob a liderança do padre Cícero Romão Batista, no intuito de derrubar do poder o novo interventor do Estado. Disponível em: < https://vestibular.uol.com.br/resumo-das-disciplinas/historia-do-brasil/movimentos-sociais-no-brasil--periodo-republicano.htm> Acesso em: 10 jul. 2020.

34 Ocorrido entre os anos 1912-1916, nas regiões do Paraná e Santa Catarina, envolvendo messianismo, pobreza e insensibilidade política. O estopim da guerra foi a construção da estrada de ferro ligando São Paulo a Santa Catarina. Disponível em: < https://vestibular.uol.com.br/resumo-das-disciplinas/historia-dobrasil/movimentos-sociais-no-brasil---periodo-republicano.htm> Acesso em: 10 jul. 2020.

35 FACÓ, 2018, p. 6; 7.

Protestantismo em Revista | São Leopoldo | v. 46, n. 01 | p. 148-167| Jan./jun. 2020

Disponível em: <http://periodicos.est.edu.br/index.php/nepp> 
armas - e o fizeram sempre - apresentavam-nos como fanáticos, isto é, insubmissos religiosos extremados e agressivos ${ }^{36}$.

A história do cangaceiro e dos fanáticos é uma linha tênue destacada pelo autor. Se por um lado o sentimento religioso fez despertar a fúria do poder dominante com várias interpretações em relação ao fanatismo religioso, por outro, foi o alvorecer da justiça social para a minoria pobre e escravizada pelo poder dominante.

\begin{abstract}
É também o reconhecimento de que aqueles homens que empunhavam armas e se tornavam cangaceiros, ou que se reuniam em torno de um monge ou conselheiro e eram chamados de fanáticos, não passavam na realidade de vítimas de uma monstruosa organização social que se está modificando hoje ao sopro das vertiginosas transformações por que passa o mundo contemporâneo e que nos envolvem, sacudindo a letargia em que vivia o nosso interior. Mais do que isso, foram aqueles miseráveis sertanejos os precursores do surgimento de um espírito inconformado que haveria de criar mais tarde uma situação revolucionária para a destruição completa daquele estado de coisas anti-humano ${ }^{37}$.
\end{abstract}

Assim, constatam-se mediante algumas inferências na história de Canudos questões antagônicas de ambos os lados. São patentes os conflitos religiosos, tanto do Catolicismo romanizado, envolvendo bispos na defesa da República, quanto do próprio Antônio Conselheiro, em nome do Catolicismo tradicional e monárquico. Ao que parece, os conflitos envolvendo República e Sertão, de cunho religioso, tinham como pano de fundo interesses políticos e econômicos. Pode-se conjecturar, mediante esta premissa, que a violência religiosa se configura de ambas as partes. Todavia, numa perspectiva sociológica, movida pelo sentimento religioso, e não, necessariamente, pela religião, a comunidade de Belo Monte é vista como lugar de igualdade e justiça social.

Considerando estas ambiguidades, é possível fazer um recorte epistemológico da violência religiosa a partir deste sentimento que toma o ser humano. É neste recorte que propomos a seguinte indagação: embora seja salutar, na perspectiva sociológica, a promoção da igualdade e justiça social na comunidade, o que se pode deduzir do comportamento do líder do acampamento, é messiânico ou patológico? Ainda sendo de viés patológico, até que ponto o sentimento religioso se constitui uma barbárie no contemporâneo?

\title{
Antônio Conselheiro: messias e psicótico?
}

Segundo Salgado ${ }^{38}$ a "Organização Mundial de Saúde (OMS) definiu, em 22 de janeiro de 1998, que 'saúde é um estado dinâmico de completo bem-estar físico, mental, espiritual e social, e não meramente a ausência de doença ou enfermidade'". A espiritualidade não é vista como patológica, mas como parte da saúde integral do indivíduo. Todavia, não é qualquer espiritualidade que promove a saúde mental. A religião também pode ser fonte de adoecimento. Segundo Neto, a "religião é provavelmente a instituição humana mais antiga e duradoura, sendo praticamente impossível separá-la da história da cultura humana. Sua

\footnotetext{
36 FACÓ, 2018, p. 7.

FACÓ, 2018, p. 8.

38 SALGADO, Mauro Ivan. Saúde e espiritualidade. Boletim, UFMG, no 1551 - Ano 32, 9.10.2006.
}

Protestantismo em Revista | São Leopoldo | v. 46, n. 01 | p. 148-167| Jan./jun. 2020

Disponível em: <http://periodicos.est.edu.br/index.php/nepp> 
influência é ambígua, tendo inspirado o que há de melhor no ser humano, e também o que há de pior"39.

Conquanto a religião seja um bálsamo para os tempos de aflição, ao mesmo tempo "está associada com a opressão dos que seguem suas doutrinas e perseguição das pessoas, especialmente se são de outra religião ou em nada creem" ${ }^{40}$. Na história de Canudos, tanto os Católicos romanizados quanto os católicos tradicionais se valem de sua religiosidade para a prática de opressão. De forma pontual, esta foi a tônica de Antônio Conselheiro:

Essa ligação entre a formação histórica do arraial, a centralidade do movimento ao redor de um místico, e a propensão para o uso da violência tem sido analisada como parte integrante de movimentos de conotação messiânico-milenaristas. Maria Isaura Pereira de Queiroz [...] considera Antônio Conselheiro o 'mais estudado messias brasileiro', cuja pregação, praticamente, era a condenação da República, vista por ele como 'o reinado do Anticristo', o 'indício seguro de que o fim do mundo não tardava e contaminara já a própria Igreja Romana, que não escapava também de suas objurgatórias' ${ }^{\prime 1}$.

Sonhos e frustrações, promessa de paz e violência configuram o céu na terra em Belo Monte.

Canudos/Belo Monte foi seguramente um movimento político-religioso que teve como motivação as frustrações, os sonhos e a esperança de milhares de camponeses nordestinos. Esse sonho coletivo terminou no dia 5 de outubro de 1897, em um massacre inominável, no final de uma guerra que provocou mais de vinte mil mortos; a cidadela foi queimada e dinamitada com milhares de cadáveres insepultos; centenas ou milhares de prisioneiros degolados por soldados ávidos de vingança; dezenas e dezenas de crianças ("jaguncinhos") distribuídas entre os vencedores como botim [sic] de guerra e levadas para longe do campo de batalha ${ }^{42}$.

Em seu texto, ao revisitar a história do Protestantismo e sua ação no contexto da guerra de Canudos, Campos ${ }^{43}$ afirma:

há que se acrescentar que o protestantismo, apesar de ter lançado mão, muitas vezes, de armas para defender-se de seus adversários, e de ter nascido de uma ampla revolta contra a ordem política e religiosa, tão logo instalado numa zona de conforto passava ao culto da ordem e à pregação do respeito aos poderosos.

É a violência religiosa que usa o poder para subjugar pessoas. É a religião da opressão que, conforme preconizado por $\mathrm{Neto}^{44}$, não é benéfica para a saúde mental. E Antônio Conselheiro, como categorizá-lo: um messias ou um psicótico? Para Neto, "importantes movimentos sociais no Brasil, como as revoltas de Canudos e do Contestado, possuem

39 NETO, Lotufo. Psiquiatria e religião: a prevalência de transtornos mentais entre ministros religiosos. Tese apresentada à Faculdade de Medicina da Universidade de São Paulo para obtenção do título de Livre-docente junto ao Departamento de Psiquiatria. São Paulo, 1997. p. 1.

40 NETO, 1997, p. 1.

41 CAMPOS, 2017, p. 39.

42 CAMPOS, 2017, p. 39.

43 CAMPOS, 2017, p. 45.

44 Cf. NETO, 1997, p. 30-36.

Protestantismo em Revista | São Leopoldo | v. 46, n. 01 | p. 148-167| Jan./jun. 2020

Disponível em: <http://periodicos.est.edu.br/index.php/nepp> 
características de movimentos messiânicos, nasceram da religiosidade popular, fruto da miséria, do isolamento e de líderes provavelmente portadores de psicopatologia" ${ }^{45}$.

Por Psicopatologia entende-se como "o conjunto de conhecimentos referentes ao adoecimento mental do ser humano" ${ }^{46}$, tendo como campo de ação

[...] um grande número de fenômenos humanos especiais, associados ao que se denominou historicamente de doença mental. São vivências, estados mentais e padrões comportamentais que apresentam, por um lado, uma especificidade psicológica (as vivências dos doentes mentais possuem dimensão própria, genuína, não sendo apenas "exageros" do normal) e, por outro, conexões complexas com a psicologia do normal (o mundo da doença mental não é um mundo totalmente estranho ao mundo das experiências psicológicas "normais") 47 .

Ao classificar os sintomas psicopatológicos, é imprescindível a análise da forma e dos conteúdos de tais sintomas.

[...] a forma dos sintomas, isto é, sua estrutura básica, relativamente semelhante nos diversos pacientes (alucinação, delírio, ideia obsessiva, labilidade afetiva, etc.), e seu conteúdo, ou seja, aquilo que preenche a alteração estrutural (conteúdo de culpa, religioso, de perseguição, etc.) $)^{48}$.

Os sintomas estão relacionados aos temas centrais da existência humana, tais como "sobrevivência e segurança, sexualidade, temores básicos (morte, doença, miséria, etc.), religiosidade, entre outros" ${ }^{49}$, fazendo parte da constituição psicopatológica. O contexto de miséria, a obsessão doutrinária religiosa, o anseio por esperança e liberdade formam o sentimento religioso que podem desencadear patologias. Tal contexto é perceptível no modo de vida desenvolvida pelos conselheiristas. Miséria aliada ao modo imperialista do Brasil República com o monopólio da terra. Talvez, por isto, o desenvolvimento do "fanatismo" que, segundo Facó ${ }^{50}$, é um termo equivocado para designar os seguidores de Antônio Conselheiro.

Autores como Campos $^{51}$, Leão ${ }^{52}$, Moura ${ }^{53}$ destacam a natureza da crise política, econômica, social e religiosa de Canudos. Do ponto de vista religioso, Campos afirma: "Nos meios católicos não se rezaram missa alguma pela alma dos seguidores do Conselheiro ou do próprio Antônio Maciel ${ }^{15}$. Houve, no entanto, missas quando da ida de soldados para o front e, depois, em favor da alma dos que morreram em ação ou na volta dos 'vencedores' 16 "54.

45 2008, p. 28. Disponível em < http://pablo.deassis.net.br/wp-content/uploads/Psicopatologia-e-semiologiados-transtornos-mentais-Paulo Dalgalarrondo.pdf > Acesso em: 30 nov. 2015.

47 DALGALARRONDO, 2008, p. 28.

48 DALGALARRONDO, 2008, p. 28, 29.

49 DALGALARRONDO, 2008, p. 29.

50 FACÓ, 2018, p. 13. O ponto de vista do autor é que o cangaceirismo e o fanatismo tiveram motivações internas e externas. Dentre estas causas estão o monopólio da terra, constituindo, assim, o domínio imperialista.

51 CAMPOS, 2017, p. 37-59.

52 LEÃO, 2015, p. 13-17.

53 MOURA, 2000, p. 21-61.

54 CAMPOS, 2017, p. 50.

Protestantismo em Revista | São Leopoldo | v. 46, n. 01 | p. 148-167| Jan./jun. 2020

Disponível em: <http://periodicos.est.edu.br/index.php/nepp> 
Como sobreviver em meio às adversidades da vida? As crises existenciais e o contexto de vida social produzem patologias severas. É o caso do fenômeno psicótico na abordagem psicanalítica. Conflito entre sujeito e família, bem como a relação conflitante do psicótico com a realidade estão imbricados neste fenômeno. Em sua análise das obras freudianas, Costa afirma: "Na grande maioria dos textos freudianos dedicados a pensar a psicose, a investigação se direciona, especialmente, para duas questões: a) a recusa do ego em relação a um fragmento da realidade e b) a alteração/divisão do ego provocada por tal recusa" 55 . É óbvio, como admite a autora ${ }^{56}$, que há variações conceituais ao longo da obra de Freud, principalmente no que diz respeito a neurose e a psicose, mas o elemento de desconexão com a realidade, mediante pensamentos delirantes, permanece.

Na neurose, o ego, em sua dependência da realidade, suprime um fragmento do id. Na psicose, acontece algo inverso, o ego, a serviço do id, se afasta de um fragmento da realidade. No lugar do recalcamento na neurose, ocorre a Verleugnung (recusa da realidade interna e externa) na psicose ${ }^{57}$.

E acrescenta:

[...] a diferença da reação do sujeito diante do evento traumático irá interferir no desfecho defensivo, ao invés do processo pelo qual haverá a alteração do ego e seu possível distanciamento da realidade. Sintetiza as distinções entre neurose e psicose na seguinte frase: 'a neurose não repudia a realidade, apenas a ignora; a psicose a repudia e tenta substituí-la'58.

A mente psicótica não tolera o desprazer e, por isso, se distancia da realidade mediante comportamentos alucinatórios e delirantes. "Na psicose, a realidade recusada é substituída por uma realidade alucinatória e, assim, a 'realidade psíquica e a externa já não se distinguem'" 59 . Na mesma direção, Dalgalarrondo afirma:

Os autores de orientação psicodinâmica tendem a dar ênfase à perda de contato com a realidade como dimensão central da psicose. O paciente psicótico, nessa perspectiva, passaria a viver fora da realidade, sem ser regido pelo princípio de realidade, e viveria predominantemente sob a égide do princípio do prazer e do narcisismo ${ }^{60}$.

É o caso da esquizofrenia, principal forma de psicose. Dalgalarrondo ${ }^{61}$ classifica os sintomas desta psicose em primeira e segunda ordem. Os sintomas de primeira ordem envolvem percepção delirante, alucinações auditivas características, eco do pensamento ou sonorização do pensamento, vivências de influência na esfera corporal e ideativa. $O$ elemento revelação, presente no messianismo, também é uma característica na esquizofrenia, pois "uma percepção absolutamente normal recebe uma significação delirante, que ocorre de

55 COSTA, Adriana Cajado. Psicanálise e saúde mental: a análise do sujeito psicótico na instituição psiquiátrica. São Luís/MA: EDUFMA, 2009. p. 69.

56 COSTA, 2009, p. 69.

57 COSTA, 2009, p. 70.

58 COSTA, 2009, p. 70,71.

59 COSTA, 2009, p. 73.

60 DALGALARRONDO, 2008, p. 327.

61 DALGALARRONDO, 2008, p. 328-331. Confira os principais conceitos e diferenciações entre as classificações dos sintomas.

Protestantismo em Revista | São Leopoldo | v. 46, n. 01 | p. 148-167| Jan./jun. 2020

Disponível em: <http://periodicos.est.edu.br/index.php/nepp> 
modo simultâneo ao ato perceptivo, em geral de forma abrupta, como uma espécie de 'revelação'”62.

O elemento afetivo está ligado no desencadeamento da psicose. No discurso avançado dos textos freudianos, ventilou-se sobre o Édipo Parental. Nesta visão, a relação com a mãe funciona como espelho para a categorização do Eu.

\begin{abstract}
O Eu é constituído pela linguagem, no decorrer da história identificatória e libidinal do sujeito. A linguagem é para o homem o caminho pelo qual ele se inscreve no discurso parental, social e cultural. É dela que signos são interiorizados para auxiliarem o Eu a construir representações ideativas do vivido, isto é, aquilo que é experienciado é transformado numa representação que possa ser pensada, falada e nomeada. O discurso materno vai falar de um "antes" do Eu, sua dimensão identificada, compreendendo-se no discurso materno sobre esse bebê, como ele foi chamado, como foram nomeadas suas vivências, quais os sentidos dados ao bebê que ele foi. Essa dimensão pode ser formulada em termos de investimento ou desinvestimento ${ }^{63}$.
\end{abstract}

No campo da segunda ordem dos sintomas esquizofrênicos estão inclusos os sentimentos afetivos. São eles: "perplexidade, alterações da sensopercepção (excluindo aqueles de primeira ordem), vivências de influência no campo dos sentimentos, impulsos ou vontade, vivência de empobrecimento afetivo, intuição delirante e alterações do ânimo de colorido depressivo ou maniatiforme" ${ }^{\prime 4}$, o que é salutar para uma possível avaliação da psicose.

Existem outras formas de psicose com relativa preservação da personalidade do indivíduo. São os transtornos delirantes (a paranoia); a esquizofrenia tardia (a parafrenia) e as psicoses breves, reativas ou psicogênicas. Alguns detalhes desta patologia são importantes: primeiro, é a possibilidade da paranoia e a parafrenia aparecerem após os quarenta anos; segundo, é que as psicoses breves podem aparecer após um evento traumático, podendo confundir-se com o estresse pós-traumático. Uma porcentagem desses casos (menos de 50\%) surge após traumas psíquicos mais ou menos intensos, "como um assalto, perder-se em uma floresta, um acidente de trânsito ou de trabalho, morte de parentes ou amigos queridos, etc." ${ }^{\prime 65}$

Fica explícito, mesmo que sucintamente, a relação da psicose com o contexto de vida, as identificações parentais e os sentimentos afetivos. Obviamente esta premissa não permite fazer juízo de valor, principalmente no que diz respeito à forma aguda da psicose, como é o caso da esquizofrenia. Considerando, porém, a biografia de Antônio Conselheiro e a possibilidade da esquizofrenia tardia e psicoses breves, acompanhado de elementos estressores, é possível traçar algumas deduções.

O médico maranhense Raimundo Nina Rodrigues (1862-1906), professor da Faculdade de Medicina da Bahia, "defendia a existência de particularidades nos negros e nos

62 DALGALARRONDO, 2008, p. 328.

63 COSTA, 2009, p. 80.

64 DALGALARRONDO, 2008, p. 329.

65 DALGALARRONDO, 2008, p. 332.

Protestantismo em Revista | São Leopoldo | v. 46, n. 01 | p. 148-167| Jan./jun. 2020

Disponível em: <http://periodicos.est.edu.br/index.php/nepp> 
mestiços brasileiros, com relação à psicopatologia e à sua imputabilidade penal"66. Desta feita, o campo de análise do autor era "definir as relações supostas entre raça/alienação mental, raça/crime e degeneração/crime; e teorizar sobre a psicologia coletiva, partindo de casos brasileiros que chamou de "loucuras epidêmicas"67.

De acordo com os parâmetros científicos da época, Nina Rodrigues defendia a premissa das diferenciações entre negros, índios e brancos, numa perspectiva de degeneração ou degenerescência mental, tendo como fatores motivadores a genética, a hereditariedade e o ambiente externo.

... as características adquiridas seriam transmitidas aos descendentes; o cruzamento de raças muito diferentes implicaria sempre degeneração física e mental dos descendentes, e essa degeneração poderia se acentuar por influencias externas, do ambiente; o mestiços seriam produtos híbridos tanto fisicamente quanto em suas manifestações intelectuais e culturais; entre os degenerados, os instintos atávicos, primitivos, poderiam ressurgir de acordo com as condições ambientais. ${ }^{68}$

Segundo Costa ${ }^{69}$, Antônio Conselheiro perdeu a mãe aos quatro anos de idade; cresceu em meio a conflitos entre o clã Maciel e o clã Araújo, envolvendo muitas mortes e emboscadas durante gerações. Já casado, perde o pai, aos vinte e sete anos. Aos vinte e nove anos, enfrenta perdas financeiras e problemas matrimoniais. Adjunto a estas crises, aos trinta anos, surge o conflito religioso com a romanização no papado de Pio IX, com a hierarquização dos bispos e a diminuição em termos de importância dos pregadores leigos, comuns no Nordeste da Bahia. Após a separação da esposa, em 1861, Antônio Conselheiro começa a sua peregrinação pelo sertão, fazendo orações e penitências.

Percebe-se uma sucessão de frustrações envolvendo os relacionamentos afetivos e a própria religião. Evidencia-se, mediante os conceitos desenvolvidos por Costa ${ }^{70}$, sobre comportamentos psicóticos, onde o Eu é constituído pela figura materna. Segundo Violante ${ }^{71}$ :

\footnotetext{
"Num primeiro momento da vida, ainda que haja precedência da voz materna, o porta-voz, o discurso dos pais, ao falar da criança, para a criança e pela criança, veicula seu desejo pelo filho e o desejo que liga o casal parental. Tais enunciados servem de emblemas identificatórios primários para a criança. É sobre esta base que se apoia a linguagem fundamental. Para além de propiciar a nomeação dos afetos e a significação dos termos do sistema de parentesco, ela vem propiciar à criança a identificação com um lugar numa rede de relações".
}

Pode-se assim, induzir por inferência, que na biografia de Antônio Conselheiro não existia esta rede de relações. Na trajetória do Conselheiro não foi permitida a polissemia de

ODA, Ana Maria Galdini Raimundo. Alienação mental e raça: a psicopatologia comparada dos negros e mestiços brasileiros na obra de Raimundo Nina Rodrigues / Ana Maria Galdini Raimundo Oda. Tese (Doutorado), Universidade Estadual de Campinas. Faculdade de Ciências Médicas. Campinas, SP: [s.n], 2003.

67 ODA, Ana Maria Galdini Raimundo. Nina Rodrigues e a loucura epidêmica de Canudos. Rev. latinoam. psicopatol. fundam. vol.3 no.2 São Paulo Apr./June 2000, p. 139.

68 ODA, 2000, p. 140.

${ }^{69}$ COSTA, 2017, p. 1-2.

70 COSTA, 2009, p. 81.

71 VIOLANTE, 1994, apud. COSTA, 2009, p. 82.

Protestantismo em Revista | São Leopoldo | v. 46, n. 01 | p. 148-167| Jan./jun. 2020

Disponível em: <http://periodicos.est.edu.br/index.php/nepp> 
sentidos, mas um sentido único da história - do Eu fixo no trauma. Pautada no pensamento de Aulagnier sobre o gatilho que impulsiona a psicose, Costa ${ }^{72}$ diz:

O conflito é identificatório, no caso da psicose, ocorre no interior do Eu, entre suas dimensões identificada e identificante. Seria no advento do Eu (estádio do espelho) que teríamos a origem da psicose, mesmo que a autora admita que a psicose é o resultado de vários acidentes de percurso durante a constituição psíquica do sujeito na infância.

Tais deduções tornam, então, Antônio Conselheiro um psicótico? À época sim. Nina Rodrigues $\mathrm{O}$ classifica com delírio crônico de Magnan, o equivalente a psicose progressiva de Garnier, divididas em quatro fases:

\begin{abstract}
A fase inicial inespecífica, uma fase de incubação, com inquietação, nervosismo, busca de explicações para os sofrimentos próprios em causas externas, em que começam as alucinações auditivas; a segunda fase, em que o delírio se coordena e se estrutura, as alucinações se intensificam, a personalidade se altera e se dissocia, há luta contra os sintomas persecutórios e disso decorre debilitação física; na terceira fase, a megalomaníaca, a desagregação mental propicia, o aparecimento de ideias de grandeza, a seguir, o delírio de perseguição se atenua, a inteligência enfraquece, preparando a quarta fase, a demência, caracterizada pela indiferença e confusão mental. ${ }^{73}$
\end{abstract}

Neste contexto as manifestações da divindade são classificadas como loucura religiosa. Todavia, devido às complexidades da literatura, principalmente quando se descartou a hipótese diagnóstica após examinar o crânio de Antônio Conselheiro quando em sua morte, torna-se inviável tal análise, mesmo permanecendo o caráter de loucura epidêmica na avaliação da Revolta dos Canudos.

Ainda assim, o que se pretende pensar é que, dependendo do contexto de vida, é possível que o líder se confunda com as visões e pensamentos supostamente vindos de Deus. Outra questão é que a classificação da religião saudável ou doentia depende do modo de ser religioso e não da religião em si. É o que preconiza $\mathrm{Neto}^{74} \mathrm{em}$ sua abordagem. No entanto é perceptível a rigidez da religião Católica romanizada/República e a Tradicional/monárquica defendida por Antônio Conselheiro. Daí a sua consequente violência. Neto apresenta as seguintes características de uma conversão com raízes patológicas:

Crença intensa, irracional e de curta duração na nova doutrina. Preocupação maior com a forma da doutrina do que com os princípios éticos e morais envolvidos. A atitude em relação à crença anterior não é moderada, nem apresenta compaixão; porém, cheia de ódio, desprezo e malevolência. Intolerância contra os que 'se desviam'. Zelo proselitista intolerante, que aliena, ao invés de atrair outros. Necessidade de martírio para provar a devoção ${ }^{75}$.

72 COSTA, 2009, p. 82.

BERCHERIE, 1989, apud. ODA 2000, p. 142.

NETO, 1997, p. 33.

NETO, 1997, p. 43.

Protestantismo em Revista | São Leopoldo | v. 46, n. 01 | p. 148-167| Jan./jun. 2020

Disponível em: <http://periodicos.est.edu.br/index.php/nepp> 
O que dizer de Antônio Conselheiro, messias e psicótico? É uma linha tênue. Conquanto haja elementos para uma psicopatologia, na literatura destaca-se o seu heroísmo, a sua devoção, a sua fé e o movimento social. Atos de coragem e esperança para os desesperados e abandonados pela religião institucional. Conforme dito, em meio à crise política e econômica, o acampamento de Belo Monte foi o alvorecer da justiça social, em busca de direitos igualitários. Todavia, não se pode descartar os efeitos nocivos de uma religião patológica. É clara a violência religiosa, tanto no pensamento daqueles que desejavam a implantação da República, quanto naqueles que repudiavam o novo sistema para a manutenção da Monarquia, em nome de Deus. Pensando sociologicamente, no entanto, o messianismo de Antônio Conselheiro foi benéfico? A sua ação sim, dizem os autores. Houve, porém, o massacre populacional. Como justificar tal ato em nome de Deus? No próximo tópico vamos considerar a linha tênue entre o messianismo e a psicose em nome de Deus.

\section{Por Uma Não Configuração da Violência Religiosa na Contemporaneidade}

O sofrimento e a dor assolam de todos os lados o sertão brasileiro. Tanto a dor da seca quanto a dor da maldade humana. As condições dos habitantes de Canudos eram desumanas, envolvendo vários fatores sociodemográficos, bem como uma deplorável situação mental ${ }^{76}$. Na doutrina sociológica de Cunha, dizem os Editores, foi "o esmagamento inevitável das raças fracas pelas raças fortes"77, uma alusão a invasão do exército na destruição do acampamento.

Neste contexto, surgem algumas questões: como classificar os atos de violência envolvendo a Guerra de Canudos? Admitindo-se que a violência configurava de ambas as partes, podemos pensar o ocorrido como ato de loucura? Se não, como justificar a barbárie em nome de Deus? Talvez, a questão, não seja a justificativa ou não da violência em nome de Deus, mas o contexto de opressão que os sertanejos estavam submetidos.

No pensamento marxista a "religião é o ópio do povo"78, entendida como alienação e ideologia. "A religião é então o reflexo ilusório, fantástico, das relações de dominação de classe, de exploração: as ideias religiosas exprimem, justificam e escondem a realidade da dominação. A religião é ideologia, falsa consciência" 79 . Parece que, no contexto de opressão dos sertanejos, a religião atua como força de resistência e não de opressão. Aqui, hipoteticamente, pode-se pensar na linha tênue ao discutir a violência religiosa.

Zabatiero ${ }^{80}$, ao analisar a História de Israel pelo ponto de vista sociocultural, traz um novo olhar para a construção histórica de Israel envolvendo imbricadas guerras. Numa leitura sociológica, aliada a conceitos marxistas e múltiplas interpretações bíblicas ${ }^{81}$, os conflitos são de cunho emancipatório. Neste modelo, "o historiador norte-americano adota explicitamente um interesse emancipatório e reconstrói a história de Israel a partir de conceitos marxistas e

76 CUNHA, 1904, p. 23.

77 CUNHA, 1904, p. 24.

78 LESBAUPIN, Ivo. Marxismo e religião. In: TEIXEIRA, Faustino (Org.). Sociologia da religião: enfoques teóricos. Petrópolis, RJ: Vozes, 2011.

79 LESPAUPIN, 2011, p. 16.

80 ZABATIERO, Júlio Paulo Tavares. Uma história cultural de Israel. São Paulo: Paulus, 2013. p. 43-49.

81 ZABATIERO, 2013, p. 44. No texto apresenta leituras contemporâneas da Bíblia, como a latina americana, com perspectiva emancipatória versus leituras de cunho objetivante. Destaca, como exemplo, as leituras populares da Bíblia.

Protestantismo em Revista | São Leopoldo | v. 46, n. 01 | p. 148-167| Jan./jun. 2020

Disponível em: <http://periodicos.est.edu.br/index.php/nepp> 
da valorização do 'povo' como agente histórico-social"82. Seria este o caso dos sertanejos liderados por Antônio Conselheiro?

A religião é parte inerente do ser humano. A marca de todas as religiões, diz Alves, é "pensar a realidade toda a partir da exigência de que a vida faça sentido"83. Para Eliade "a manifestação do sagrado funda ontologicamente o mundo" ${ }^{84}$. No entanto, ao mesmo tempo em que confere sentido e força existencial, é uma força avassaladora que arrebata os sentidos para práticas perversas. É o fenômeno das experiências não naturais e ou irracionais que a religião trabalha. Tais experiências advêm do "sentimento de pavor diante do sagrado, diante desse mysterium tremendum, dessa majestas que exala uma superioridade esmagadora de poder; encontra o temor religioso diante do mysterium fascinans, em que se expande a perfeita plenitude do ser"85.

Todavia este caráter de irracionalidade não deve ser tomado pelo ponto de vista negativo, pois, "a experiência do sagrado torna possível a 'fundação do mundo'; lá onde o sagrado se manifesta no espaço, o real se revela, o Mundo vem a existência" ${ }^{86}$. Mas como discernir uma experiência religiosa positiva da negativa? Atendendo ao objetivo deste tópico, qual a linha tênue entre o messianismo e a patologia, evitando, assim, a violência religiosa?

Providello e Yasui ${ }^{87}$, a partir da obra de Foucault, afirma que a loucura é objeto historicamente constituído. Assim, "a loucura não pode ser encontrada no estado selvagem. A loucura só existe em uma sociedade, ela não existe fora das normas da sensibilidade que a isolam e das formas de repulsa que a excluem ou capturam" ${ }^{88}$. Neste caso, os profetas, bruxos, sacerdotes e visionários da Idade Média não ganhavam o status de louco.

\footnotetext{
Segundo Foucault, os loucos, na Idade Média, pertenciam de certa forma ao horizonte social, pois havia uma experiência trágica da loucura que os conectava ao mundo como aqueles que dizem a verdade de forma extravagante, uma experiência que dava a eles o lugar da revelação. Isso quer dizer que a loucura tinha uma linguagem aceita socialmente, mesmo com suas particularidades ${ }^{89}$.
}

Mas Alminhana e Menezes Jr. ${ }^{90}$ trazem novas luzes à questão. Segundo os autores "Algumas experiências religiosas e/ou espirituais apresentam um caráter dissociativo" 91 , explorando, nos estudos, o caráter saudável e patológico destas experiências. Conquanto não sejam conclusivas, as suas pesquisas afirmam que:

82 ZABATIERO, 2013, p. 44.

83 ALVES, Rubens. O que é religião? Coleção primeiros passos. Disponível em: < http://files.direito pucminas.webnode.com.pt/200000356a6e11a7db0/Rubens\%20Alves\%20\%200\%20Que\%20\%C3\%A9\%20R eligi\%C3\%A3o.pdf> Acesso em: 21 dez. 2018. p. 3.

84 ELIADE, Mircea. O sagrado e o profano: a essência das religiões. Tradução Rogério Fernandes. 3o. ed. São Paulo: Editora WMF; Martins Fontes, 2010, p. 26.

85 OTTO, 1917, apud. ELIADE, 2010, p. 16.

86 ELIADE, 2010, p. 59.

87 PROVIDELLO, Guilherme Gonzaga Duarte; YASUI, Silvio. A loucura em Foucault: arte e loucura, loucura e desrazão. História, Ciências, Saúde - Manguinhos, Rio de Janeiro, v.20, n.4, out. / dez. 2013, p.1515-1529.

88 FOUCAULT, 2006, apud. PROVIDELLO; YASUI, 2013, p. 1517.

89 FOUCAULT, 2006, apud. PROVIDELLO; YASUI, 2013, p. 1517-1518.

90 ALMINHANA, Leticia Oliveira. MENEZES JR., Adair. Experiências Religiosas/Espirituais: dissociação saudável ou patológica? Horizonte, Belo Horizonte, v. 14, n. 41, p. 122-143, jan. / mar. 2016. p. 122-143.

91 ALMINHANA e MENEZES JR, 2016, p. 122.

Protestantismo em Revista | São Leopoldo | v. 46, n. 01 | p. 148-167| Jan./jun. 2020

Disponível em: <http://periodicos.est.edu.br/index.php/nepp> 
Experiências religiosas/espirituais de caráter dissociativo (como a possessão), podem ser consideradas saudáveis se apresentarem ausência de sofrimento, controle, forem contextualizadas e trouxerem benefício para o indivíduo. Indivíduos sem Auto direcionamento e com experiências autocentradas mostram maior probabilidade de desenvolver patologia ${ }^{92}$.

Os pensamentos delirantes e os comportamentos alucinatórios são sintomas da esquizofrenia. Mas seriam tais pensamentos uma patologia no messianismo-milenarista com as suas visões de futuro e profecias? Mendonça ${ }^{93}$ ao fazer uma análise do conceito de sagrado na obra de Bastide diz: "o sagrado ainda permanece um enigma" ${ }^{44}$. Com esta premissa desenvolve o elemento da esperança que é possível mediante o ressurgir do sagrado. Nesta linha de raciocínio, o que ocorre com Antônio Conselheiro não é uma patologia, mas o alvorecer da esperança quando a alma humana está diante de uma crise ${ }^{95}$. "Esse temor da morte, sempre presente no homem ao ver constantemente sua esperança ser ameaçada, provoca utopias religiosas e políticas que tentam superar o estado anômico, tanto social quanto religioso" ${ }^{\prime 96}$. É neste contexto que se reflete a selvageria do sagrado, bem como os ofícios profético, sacerdotais e políticos.

As utopias todas são geradas por aquela força irreversível da esperança presente nos arcanos desconhecidos do ser humano e objetivada na 'selvageria' do sagrado em turbulência. Na religião, seus profetas podem criar novas formas ou alterar as já existentes, e, na política, o efeito pode ser o surgimento de tiranias ou populismos. No primeiro caso, os profetas logo se transformam em sacerdotes, e, no segundo, os tiranos e populistas podem se converter em heróis destinados a finais melancólicos ou, às vezes, trágicos ${ }^{97}$.

A religiosidade/espiritualidade promove o bem-estar e a saúde mental. No entanto, existem estratégias espirituais positivas e negativas ao lidar com as crises existenciais. Moreira e Stroppa chamam de religiosidade intrínseca e extrínseca, cada qual com as suas consequências e motivações.

Na religiosidade intrínseca, a religião tem um lugar central na vida do indivíduo, é seu bem maior. Outras necessidades são vistas como secundárias, de menor importância e, na medida do possível, são colocadas em harmonia com sua crença e sua orientação religiosa. Tendo aceitado uma religião, o indivíduo procura internalizá-la e segui-la integralmente. Na religiosidade extrínseca, a religião é um meio utilizado para obter outros fins, como consolo, sociabilidade, distração e status. Sua religião é aceita de modo superficial ou é adaptada para atender suas necessidades e seus objetivos pessoais ${ }^{98}$.

92 ALMINHANA e MENEZES JR, 2016, p. 122.

93 MENDONÇA, Antônio Gouvêa. De novo o sagrado selvagem: variações. Estudos de Religião, Ano XXI, n. 32, 22-33, jan. / jun. 2007, p. 22-33.

94 MENDONÇA, 2007, p. 23.

95 Cf. MENDONÇA, 2007, p. 24. O conceito Espeleologia da Alma é desenvolvido na obra de Bastide, onde o ser humano extrai em suas raízes, a partir de utopias religiosas, forças para superar as crises.

96 MENDONÇA, 2007, p. 24.

97 MENDONÇA, 2007, p. 24,25.

98 ALMEIDA, Alexander Moreira de. STROPPA, André. Espiritualidade e Saúde Mental: Importância e impacto da espiritualidade na saúde mental. Zen Review vol.2, p. 2-6, 2010. p. 2.

Protestantismo em Revista | São Leopoldo | v. 46, n. 01 | p. 148-167| Jan./jun. 2020

Disponível em: <http://periodicos.est.edu.br/index.php/nepp> 
É determinante, na saúde mental, a maneira como o indivíduo maneja a sua RE ${ }^{99}$. Sejam para a predição ou remissão dos transtornos depressivos, transtornos de ansiedade, transtorno afetivo bipolar, esquizofrenia, dependência de substâncias e suicídio ${ }^{100}$. Assim, no que diz respeito à configuração da violência religiosa de Canudos são duas faces da mesma moeda. Seja na defesa do poder instituído ou na transgressão a este poder. É o jogo de dominado e dominadores. É a dinâmica das religiões, o sagrado instituinte e instituído. De onde procedem estas forças de dominação e de libertação dos dominadores em nome da divindade? Da experiência com o sagrado, diz Mendonça. "Originando-se do transe, cheganos em forma de palavra, de discurso, já intermediado, portanto, [...] ele desponta nas hierofanias e logo se transforma em discurso produzido pelo sujeito da experiência religiosa"101. Sendo que, da parte dos dominados (Os Canudos), o que restou foi o massacre, previsão acentuada por Mendonça, quando o sagrado instituinte tenta sobrepor-se ao sagrado instituído ${ }^{102}$.

\section{Considerações Finais}

Conforme a proposta da pesquisa, é uma linha tênue. Como classificar o que é normal ou patológico nas experiências religiosas? Justifica, em nome de Deus, a violência, seja física ou psicológica, mesmo que para fins sociais? Talvez a Guerra de Canudos não nos dê respostas devido à linha paradoxal entre a violência religiosa dos bispos católicos, na defesa do poder dominante, versus a violência religiosa dos conselheiros que, de igual modo, promove a guerra em nome da paz e da justiça social.

A provocação, no entanto, é pertinente. É possível, a partir das experiências negativas da vida, o desenvolvimento de patologias, como exemplificado na psicose, possíveis revelações em nome de Deus. Neste ponto, vale a reflexão para o contemporâneo. Sendo possível que a RE contribua de forma negativa ou positiva para a saúde mental, é de grande valia refletir, principalmente os líderes religiosos, se a postura traz benefícios ou malefícios para os seus seguidores.

Não tendo como classificar, a partir da história de Canudos, se o líder Antônio Conselheiro foi um messias e um psicótico, para que evite novas configurações de violência religiosa no contemporâneo, vale ressaltar que nem tudo em nome de Deus significa, de fato, seja revelação de Deus. À guisa de conclusão, enquanto caminho reflexivo, vale pensar a religião patológica e saudável proposta por Neto (1997, p. 52) e, assim, discernir entre o bem e o mal, advindos do universo religioso.

\section{Referências}

ALMEIDA, Alexander Moreira de. STROPPA, André. Espiritualidade e Saúde Mental: Importância e impacto da espiritualidade na saúde mental. Zen Review vol. 2, p. 2-6, 2010.

99 Sigla utilizada por Almeida e Stroppa (2010) para Religiosidade e Espiritualidade.

100 MOREIRA; STROPPA, 2010, p. 1-6.

101 MENDONÇA, 2007, p. 25.

102 MENDONÇA, 2007, p. 25.

Protestantismo em Revista | São Leopoldo | v. 46, n. 01 | p. 148-167| Jan./jun. 2020

Disponível em: <http://periodicos.est.edu.br/index.php/nepp> 
ALMINHANA, Leticia Oliveira. MENEZES JR., Adair. Experiências Religiosas/Espirituais: dissociação saudável ou patológica? Horizonte, Belo Horizonte, v.14, n. 41, p. 122-143, jan. / mar. 2016.

ALVES, Rubens. O que é religião? Coleção primeiros passos. Disponível em: < http://files.direitopucminas.webnode.com.pt/200000356a6e11a7db0/Rubens\%20Alves\%20 \%200\%20Que\%20\%C3\%A9\%20Religi\%C3\%A3o.pdf> Acesso em: 21 dez. 2018.

CAMPOS, Leonildo Silveira. Ecos da "Guerra de Canudos" em dois Jornais Protestantes de São Paulo (1896-1897). Estudos de Religião, v. 31, n. 1, p. 37-59, jan.-abr. 2017.

COSTA, Adriana Cajado. Psicanálise e saúde mental: a análise do sujeito psicótico na instituição psiquiátrica. São Luiz/MA: EDUFMA, 2009.

COSTA, Carla. Cronologia resumida da Guerra de Canudos. Museu da República, IBRAM/Minc, outubro de 2017, p. 1. Disponível em: <http://museudarepublica.museus.gov.br/wpcontent/uploads/2017/10/CronoCanudos.pdf> Acesso em: 12 dez. 2018.

CUNHA, Euclydes da. Os sertões: campanha dos canudos. 2. ed. Rio de Janeiro: LAEMMERT \& C, 1904.

DALGALARRONDO, Paulo. Estudos sobre religião e saúde mental realizados no Brasil: histórico e perspectivas atuais. Rev. Psiq. Clín. 34, supl. 1; 25-33, 2007.

. Psicopatologia e semiologia dos transtornos mentais. 2. ed. Porto Alegre: Artmed, 2008. Disponível em < http://pablo.deassis.net.br/wp-content/uploads/Psicopatologia-esemiologia-dos-transtornos-mentais-Paulo Dalgalarrondo.pdf > Acesso em: 30 nov. 2015.

ELIADE, Mirceia. O sagrado e o profano: a essência das religiões. Tradução Rogério Fernandes. 3‥ ed. São Paulo: Editora WMF; Martins Fontes, 2010.

FACÓ, Rui. Cangaceiros e Fanáticos: gênese e lutas. Disponível em: <https://www.marxists.org/portugues/faco/1963/03/cangaceiros.pdf> Acesso em: $19 \mathrm{dez}$. 2018.

JUNQUEIRA, Eduardo. Guerra de Canudos. Disponível em: <https://cpdoc.fgv.br/sites/default/files/verbetes/primeirarepublica/GUERRA\%20DE\%20CA NUDOS.pdf> Acesso em: 12 dez. 2018.

Leão, Maria Beatriz da Costa Baptista de. A Guerra de Canudos e a cultura republicana nos jornais da capital federal. Dissertação (Mestrado) -Pontifícia Universidade Católica do Rio de Janeiro, Departamento de História, 2015.

LESBAUPIN, Ivo. Marxismo e religião. In: TEIXEIRA, Faustino (Org.). Sociologia da religião: enfoques teóricos. Petrópolis, RJ: Vozes, 2011.

MARTINS, Paulo Emílio Matos. Canudos: organização, poder e o processo de institucionalização de um modelo de governança comunitária. Cadernos EBAPE. BR, v. 5, no 4, dez. 2007.

MENDONÇA, Antônio Gouvêa. De novo o sagrado selvagem: variações. Estudos de Religião, Ano XXI, n. 32, 22-33, jan. /jun. 2007.

MOURA, Clóvis. Sociologia política da guerra camponesa de Canudos: da destruição do Belo Monte ao aparecimento do MST. 1. ed. Editora Expressão Popular: São Paulo, 2000. p. 14.

Protestantismo em Revista | São Leopoldo | v. 46, n. 01 | p. 148-167| Jan./jun. 2020

Disponível em: <http://periodicos.est.edu.br/index.php/nepp> 
Disponível

em:

<http://www.reformaagrariaemdados.org.br/sites/default/files/Sociologia\%20pol\%C3\%ADti ca\%20da\%20guerra\%20camponesa\%20de\%20Canudos\%20\%20da\%20destrui\%C3\%A7\%C3\% A3o\%20do\%20Belo\%20Monte\%20ao\%20aparecimento\%20do\%20MST\%20\%20Cl\%C3\%B3vis \%20Moura\%20\%20Express\%C3\%A30\%20Popular\%20-\%202000.pdf> Acesso em: 12 dez. 2018.

NETO, Lotufo. Psiquiatria e religião: a prevalência de transtornos mentais entre ministros religiosos. Tese apresentada à Faculdade de Medicina da Universidade de São Paulo para obtenção do título de Livre-docente junto ao Departamento de Psiquiatria. São Paulo, 1997.

NOGUEIRA, Ana Paula dos Santos. Canudos: uma história de morte, na luta pela vida. Disponível em: <http://www.uesb.br/anpuhba/artigos/anpuh_l/ana_paula_santos_nogueira.pdf> Acesso em: 12 dez. 2018.

ODA, Ana Maria Galdini Raimundo. Alienação mental e raça: a psicopatologia comparada dos negros e mestiços brasileiros na obra de Raimundo Nina Rodrigues / Ana Maria Galdini Raimundo Oda. Tese (Doutorado), Universidade Estadual de Campinas, Faculdade de Ciências Médicas. Campinas, SP: [s.n], 2003.

ODA, Ana Maria Galdini Raimundo. Nina Rodrigues e a loucura epidêmica de Canudos. Rev. latinoam. psicopatol. fundam. vol.3 no.2 São Paulo Abr./Jun. 2000.

PROVIDELLO, Guilherme Gonzaga Duarte; YASUI, Silvio. A loucura em Foucault: arte e loucura, loucura e desrazão. História, Ciências, Saúde - Manguinhos, Rio de Janeiro, v.20, n.4, out. /dez. 2013, p.1515-1529.

SALGADO, Mauro Ivan. Saúde e espiritualidade. Boletim, UFMG, № 1551 - Ano 32, 9.10.2006.

SCHWARCZ, Lilia M.; STARLING, Heloísa M. Brasil: uma biografia. São Paulo: Companhia das Letras, 2015. Acervo Eletrônico. Disponível em: <https://docero.com.br/doc/s5n0c> Acesso em: 10 jul. 2020.

WANDERLEI, Leandro Aquino. Religiosidade e conflito no sertão conselheirista: o antagonismo entre a arquidiocese de Salvador e Antônio Conselheiro/Canudos. Anais do XXVI Simpósio Nacional de História - ANPUH. São Paulo, julho 2011.

ZABATIERO, Júlio Paulo Tavares. Uma história cultural de Israel. São Paulo: Paulus, 2013. 